\title{
Women and health professionals' perspectives on a conditional cash transfer program to improve pregnancy follow-up: a qualitative analysis of the NAITRE randomized controlled study
}

\section{AURELIE GODARD MARCEAU ( $\nabla$ amarceau@chu-besancon.fr )}

CHU Besancon: Centre Hospitalier Universitaire de Besancon https://orcid.org/0000-0002-1019-8300

Nicolas Meunier Beillard

CHU Dijon: Centre Hospitalier Universitaire de Dijon

Philippe Deruelle

CHRU de Lille: Centre Hospitalier Universitaire de Lille

Mathieu Morin

CHU Toulouse: Centre Hospitalier Universitaire de Toulouse

Claude Virtos

Centre Hospitalier de Dreux

Astrid Eckman-Lacroix

CHU Besancon: Centre Hospitalier Universitaire de Besancon

\section{Elodie Debras}

APHP: Assistance Publique - Hopitaux de Paris

\section{Laurent Laforet}

CHU Dijon: Centre Hospitalier Universitaire de Dijon

Marc Bardou

CHU Dijon: Centre Hospitalier Universitaire de Dijon

\section{Research}

Keywords: Pregnancies, Low-Income Populations, CCT program, Qualitative Research, Ethics

Posted Date: December 11th, 2020

DOI: https://doi.org/10.21203/rs.3.rs-124363/v1

License: (c) (i) This work is licensed under a Creative Commons Attribution 4.0 International License.

Read Full License 


\section{Abstract}

Objectives. Many types of conditional cash transfer (CCTs) programs have been developed and their effects demonstrated, including programs to improve prenatal care, but ethical critiques have included paternalism and lack of informed choice. These criticisms were levelled the French NAITRE randomized clinical trial, which is assessing a CCT program that promotes prenatal care among women of low socioeconomic backgrounds. We conducted qualitative research to determine if women in the study and health professionals (HP) shared these concerns.

Study design. We conducted a multicenter, cross-sectional, qualitative study of 26 participating postdelivery women and $8 \mathrm{HP}$ (physicians and midwives, participants and non-participants) to assess their perspectives on CCT, purposively selecting a sample of women with diverse experiences. We excluded women who had miscarried or whose babies had died, or whose new-born suffered from a severe medical condition. We invited health professionals to participate even if they or their center had not participated in the trial. Participants agreed to semi-structured face-to-face or phone interviews, which we recorded as audio and transcribed. Our approach to identifying patterns was inductive; we highlighted topics that repeatedly emerged, characterized them, and organized them into themes.

Results. Women expressed surprise that the CCT was offered, but did not perceived it negatively. They never mentioning feeling stigmatized. They described CCT as a significant source of aid for women with limited financial resources. HP described the CCT in less positive terms, e.g., expressing concern about discussing cash transfer at their first medical encounter with women. Though they emphasized ethical concerns about the basis of the trial, they recognized that CCT needed to be evaluated.

Conclusion. In France, a high-income country where prenatal follow-up is free, health professionals were concerned that the CCT program would change their relationship with patients and wondered if it was the best use of funding, but women who received a cash incentive said they did not feel stigmatized and indicated that these payments helped them prepare for their baby's birth.

Trial registration: NCT02402855- Clinical Trial - first registration 30 march 2015 -

\section{Highlights}

- Conditional cash transfer (CCT) programs may improve adherence to health-preventive services like antenatal follow-up

- CCT is sometimes described as a paternalistic approach that suppresses free choice.

- Women who received CCT viewed it positively and used the money to buy things for their babies and families.

- Health professionals were concerned that CCT was unjust and that it might change their relationships with their patients.

- Women did not feel stigmatized by their participation in the CCT program. 


\section{Plain English Summary}

The French NAITRE randomized clinical trial is assessing a conditional cash transfer program that promotes prenatal care among women of low socioeconomic backgrounds. Some ethics concerns were edicted such as paternalism and lack of informed choice. We conducted qualitative research to determine if women in the study and health professionals (HP) shared these ethics concerns. 26 post-delivery women and 8 Health Professionals (physicians and midwives, participants and non-participants) were included.

Women expressed surprise that the cash was offered, but did not perceived it negatively. They never mentioning feeling stigmatized. They described cash transfer program as a significant source of aid for women with limited financial resources. Health professional described the cash transfer program in less positive terms but they recognized that CCT needed to be evaluated.

In France, a high-income country where prenatal follow-up is free, health professionals were concerned that the CCT program would change their relationship with patients and wondered if it was the best use of funding, but women who received a cash incentive said they did not feel stigmatized and indicated that these payments helped them prepare for their baby's birth.

\section{Statement Of Significance}

What is Already Known

\section{What is already known about this subject?}

In France's national health insurance system, a highly structured system of pregnancy monitoring and follow-up has been in place since the 1970 s, but $36 \%$ of women in unstable living conditions still consult a physician fewer than eight times during pregnancy. Premature birth is most frequent in this group. Pregnancy monitoring improved after cash transfer programs (CCT) were implemented in developing countries, and CCT improved certain health behaviors in European countries.

\section{What does this paper add?}

Health professionals may be uncomfortable with CCT programs, especially if they are unused to navigating monetary relationships with their patients (e.g., hospital professionals). CCTs raise ethical issues we need to understand, both from the perspective of participating health professionals and patients. We designed this qualitative study to elicit those perspectives from women participating in the ongoing NAITRE CCT intervention study in France, and from participating and non-participating health care workers. Our results suggest that professional resistance to these programs springs from a perceived lack of equity and concerns about stigmatization, but that the women who participate in the CCT program view it in a positive light and do not describe being stigmatized.

\section{Implications for practice, theory, or policy}


We found that participating women viewed the CCT program positively and felt they suffered no harm. If the program also improves the health outcomes of participating women and their newborns, the NAITRE study should encourage us to devise and test other similar programs targeting patients in precarious economic circumstances.

\section{Introduction}

Women with fewer socio-economic resources have higher risk of adverse maternal outcomes, especially gestational diabetes (1). Women in precarious living situations attend fewer medical appointments during pregnancy; poor follow-up during pregnancy doubles a woman's risk of severe maternal and neonatal morbidity $(2,3)$. Socio-economically disadvantaged women may not attend follow-up because they lack financial resources (4) or must surmount economic or social barriers that make it hard to organize care $(5,6)$. At least eight antenatal contacts are recommended by the WHO (7); France recommends seven (8). During these visits health care professionals (HP) promote healthy behavior like smoking cessation (9), and can make early diagnoses of pregnancy-related diseases like gestational diabetes or hypertension $(10,11)$. If financial barriers limit access to care, offering women a financial incentive may improve their health behaviors; for example, incentives have increased appropriate prescription contraceptive use (12) and improved use of health facilities (13). But conditional cash transfer (CCT) programs have often been criticized for paternalism and clientelism and described as a poor use of resources (14).

Economic incentive programs are most common in low or medium income countries, including programs designed to encourage women to attend pre- and antenatal care $(2,15)$, pediatric follow-up, and to send their children to school (16). These have been associated with improved health outcomes in low-income countries $(5,8-11,13)$. A 2015 Cochrane Review found that pregnant women who received incentives were more likely (mean difference $5.84,95 \% \mathrm{Cl} 1.88$ to 9.80 ) to obtain adequate quality prenatal care, but the trials did not report on preterm birth, small for gestational age, or perinatal deaths (22). This review underlined the public health need for properly conducted randomized trials to collect sufficient data on maternal and neonatal outcome (22). High-income European countries rarely experiment with financial incentives but some initiatives have targeted specific illnesses, especially mental illnesses (10), or behaviors like smoking during pregnancy $(20,23)$.

One such initiative in a high-income country is the NAITRE study (NCT02402855), an ongoing clusterrandomized clinical trial in France that adds CCT to usual prenatal care for pregnant women of low socioeconomic background (24). Like other CCT programs, the trial has provoked critiques from health professionals and members of the regional ethics committee (Comité de Protection des Personnes Est-1) because they fear it may stigmatize women and that introducing an economic component might threaten the trust-based relationship between pregnant women and their HP.

Some of the opponents to the NAITRE study argued that CCT would not be useful in countries where prenatal care was fully covered by national health insurance, but no one tried to elicit the perspective of 
the women who would be served by the CCT program. If participating women felt they were stigmatized by the CCT, that would be a compelling reason to shut down even an effective CCT program.

We set out to answer this ethical question by conducting a qualitative study to identify the concerns of participating women and submitted our results to the data monitoring and safety committee (DSMC) at the end of the first recruitment year. The study included interviews with women in the intervention and control group of the study, and with HP, including some who had refused to participate in the project.

\section{Methods}

\section{Design of the study}

In France, health authority guidelines recommend seven antenatal visits and three ultrasound exams as the highest standard of care (8). The NAITRE study was designed to determine if superior outcomes could be achieved by adding CCT to this standard; a one-third drop in negative maternal-fetal outcomes is the threshold for superiority. NAITRE is a pragmatic multi-center, open-label cluster-randomized trial with a parallel arm design. The full protocol of the NAITRE study has been published (24). Women in the intervention group received a 30 Euros incentive payment for each of up to 6 scheduled prenatal consultations they attended after their first consultation (at which they were invited to participate in the NAITRE trial); compensation was provided for up to one consultation per month. At each participating center, women were randomized to either the control or the CCT group was the two-month periods. Women in the CCT group were given a "debit card" that could be used at any store, but would not allow them to withdraw cash at an ATM. The card was issues with a zero balance, and $30 €$ was wired to the card after qualifying antenatal visit. Women in the control group received the standard of care (7 identical visits without payment). We offered any participating woman who completed the qualitative survey a $40 €$ gift after their interview. We conducted face-to-face or phone interviews to elicit the viewpoints of participating women in antenatal care. We also interviewed health professionals (obstetricians and midwives), including some who refused to participate in the NAITRE study or who worked at centers that refused. We purposively selected women to represent a range of antenatal care and pregnancy outcomes.

\section{Participants and sample selection}

NAITRE trial eligibility criteria were: i) pregnant woman; ii) aged 18 or older; iii) attended first pregnancy consultation in a participating center before the end of their 26th week of amenorrhea; and, iv) enrolled in health insurance for low-income families (Universal Medical Coverage or Couverture Médicale Universelle, $\mathrm{CMU}$ ) or were immigrants without papers (State Medical Coverage or Aide Médicale d'Etat, AME). We excluded women i) whose language skills were insufficient to understand the study or ii) who were under legal protection. To ensure our sample of participating women reflected the range of women's experience, we chose women 3 to 6 months post-delivery based on their compliance or non-compliance with planned antenatal care and on the level and kind of complications they did or did not have during pregnancy or childbirths. We selected women of different ages, primiparous, and multiparous women. We excluded woman whose babies died or had been diagnosed with a severe medical condition at birth because we 
thought these women might not be prepared to discuss or to accurately recall their experiences during pregnancy.

We recruited from 3 inclusion centers in different areas to ensure the spectrum of precariousness would be represented (rural, urban, former industrial area, or area with high proportion of immigrants). We then asked our data manager to select women who met specific criteria (primiparous, non-adherent) from any NAITRE inclusion center to balance our sample. We sought the perspectives of women with diverse life courses that would likely have influenced their perception of medical follow-up. We contacted women by phone to inform them about the qualitative study and invited them to participate. We did not set a target size for our sample, and instead continued interviewing until we reached saturation of data and concepts.

We gathered data on the determinants of medical follow-up during pregnancy from semi-structured individual interviews. The interviewer encouraged women to describe situations that highlighted their habits, thoughts, and feelings about pregnancy and their medical care. We asked them to describe their health practices during pregnancy, visits, and specific events during pregnancy, and factors that encouraged or discouraged their adherence to scheduled prenatal care visits. We also asked women in the intervention group how they felt about the CCT incentive and if and how it aided them. We asked women in the control group: "What would you think if women were offered economic compensation every time they consulted during their pregnancy?" Interviews were held at the hospital where women had been followed-up during pregnancy or at their home; a few interviews were conducted by telephone.

In the second step of the study, we included HP whose center or unit had been asked to participate in the NAITRE study, including centers and units that had refused (24). HP were invited by email to participate in a face-to-face qualitative interview. We divided HP into three groups: i) those who worked in an inclusion center and agreed to participate; ii) those who worked in an inclusion center but declined to participate; and, iii) those who worked in a center that declined to participate in NAITRE. These semi-structured interviews encouraged HPs to describe factors that influenced their participation in NAITRE. We also asked them to describe potential facilitators or barriers to implementing and scaling up the CCT to integrate it into standard practice if the combined intervention was found to be superior (if maternal-fetal negative outcomes dropped by at least a third in this group of socioeconomically disadvantaged women).

\section{Data collection}

Two health sociology researchers working in Hospital (1 woman PhD [AGM] and 1 man Engineer [NMB]) collected the data and facilitated the interviews, which were conducted between May 2017 and July 2019; both were clinical researchers trained to conduct qualitative interviews. They used one of the two guides we developed, depending on whether they were interviewing participating women or health professionals. The guides were based on a grounded theory approach and led interviewers through a series of topics designed to elicit the data we needed to meet our study objectives. The researchers selected the topics and clinicians validated them. We tested the guides and tuned them in preliminary interviews to ensure that interviewees understood the questions and that they elicited useful information. Two guides were 
edited. For women who received CCT we asked them to describe their experience of CCT. For women in the control group, we asked them what they think about such a program. For all of them, we asked them to describe their follow-up.

All interviews were audio recorded and fully transcribed. Field notes were attached to interview transcripts and indicated if the husband was present during the interview and any effect his presence seemed to have. We continued collecting data until interviews no longer added new concepts (theoretical saturation) and we had enough data to achieve our research objectives.

\section{Data analysis}

Qualitative data analysis was initiated during data collection, when we began analyzing the raw data to extract themes. Two sociologists independently coded the interview transcriptions. We took an inductive approach to identifying patterns, highlighting topics that repeatedly emerged, characterizing them, and then organizing them into themes that we reviewed and discussed to reduce the likelihood of personal bias and to ensure analytic robustness. We then checked our themes against those described in the available literature to ensure our characterizations were complete and accurate. Finally, we summarized the themes to demonstrate the pattern of our findings.

\section{Results}

\section{$\underline{\text { Inclusion results }}$}

First, we attempted to contact all the eligible women who participated in NAITRE in the 3 inclusion centers (Besançon University Hospital, Lille University Hospital, and Robert Debré Hospital in Paris). There were 44 eligible women (February 2017- September 2017); of these, 22 were included (flow charts 1). Of these patients, only one was non-observant. Then in order to include non-adherent women, we extended our search to all the inclusion center of the NAITRE study. We selected 23 patients (18 non observant) and included 4 patients (flow charts 2). In total, we selected 67 patients and included 26 patients. Of the 26 women we interviewed, 14 had received cash payments from the program.

A professional interpreter sat in on 3 interviews and the husband translated for 2 interviewees. Husbands were present for 5 interviews. Interviews averaged 28 minutes.

HPs were recruited from a list compiled by the NAITRE team of all the 15 units that had been contacted for the study. We contacted 25 centers to request interviews with an email to the head of unit (Flow charts 3). 6 centers agreed to participate. 4 physicians and 3 midwives participated in qualitative one-on-one interviews. All physicians and 1 midwife did include patients in the NAITRE study. 2 midwifes did not include any patient - one because she refuse to do so while the center do, one because she works in a center that refused to include. To protect the confidentiality of our HP informants, we do not specify the centers involved. These interviews lasted an average of 20 minutes. 
The 14 women who received CCT described surprise when they were offered CCT, and thought it unusual for the French health system. Their astonishment was not accompanied by negative critique; these women with limited resources viewed the CCT positively. They decided how to spend the compensation and most often used it to buy essentials for the baby $(n=13)$. They used it to pay for hospital transport when getting there posed a challenge $(n=3)$, and to supplement the family budget $(n=12)$. The women made clear that the CCTs contributed to the family's well-being. Given their precarious situations, they were pleased to receive the money. Three women said they saved up several payments to buy expensive equipment for the baby (e.g., a changing table or baby gate).

Women in the non-intervention group were also surprised at the payments and several indicated that they would have refused such a proposal. One woman's husband initiated the refusal of the $40 €$ payment for participating in the qualitative interview, but all other women, including those who said they would have turned down the CCT, accepted it. Even women who said they would have refused CCT payments agreed that a cash incentive could be very helpful to "low-income women", particularly to help them prepare for their baby's arrival.

None of the women found it easy to name an amount that would encourage women to attend consultations, saying it would depend on a family's situation. They also pointed out that any size payment would benefit the family.

Two husbands objected outright to the payments. No woman objected. The first husband, (intervention group) refused to let his wife use the CCT money she had received during pregnancy follow-up and take $40 €$ incentive for the qualitative survey because he was afraid that it would allow medical staff to experiment on his unborn children He take the card and fordid his wife to use it (FP8). The second husband (control group) refused the compensation we offered at the end of the interview, saying he did not need the money and had only come to provide us with information (FP1).

Whether or not they were financially compensated during the study, all women claimed that a CCT would not have changed their behavior and that they would have attended the consultations anyway. Only one woman (non observant in intervention group) said that she hadn't needed medical follow-up during her pregnancy (FT2). 13 women recognized medical follow-up was important because they had been concerned about their health during previous pregnancies ( 8 women) and because they understood follow-up protects their infant and improves their own and their baby's health (13 women).

\section{Health professionals' perception of the CCT initiative}

$2 \mathrm{HP}$ interviewed disagreed to include patients into this study : one in a non-participate center, one in a participate center. Those who agreed to participate in the study $(n=6)$ saw CCT differently than those who did not agree $(n=2)$. The most common reason HP chose not to participate in NAITRE was the CCT. They made two arguments against compensation. First, they felt CCT programs pose ethical problems 
because it was difficult to discuss money and validate payments with users, with whom they had never discussed money. They were uncomfortable discussing money even if it was electronically transmitted to the woman's payment card by the NAITRE coordinating center. They considered talking about money with patients in precarious situations was a breach of the principle of justice and equality. Their perception of this principle was that financial aspects should never interfere with medical care. They consider $(n=5)$ that this could be stigmatizing. Second, they seemed more concerned about the study than about the principles behind the financial incentives. They worried that the study design (randomization stratified on the center with alternating control and intervention periods) could lead to women in both groups meeting in the waiting room and discussing the CCT. Women included in the NAITRE trial were only told if they were in the control or intervention group, but not given the specifics of the intervention. Professionals feared they would have to deal with dissatisfied women in the control group who felt the situation was unjust. It indeed happened, although very rarely, that women from the control group heard about the CCT. HP reported only one situation. In this case, but even if they were surprised, no woman in the control group requested money.

Some participating HP $(n=3)$ were concerned about the ethics of offering women money for attending consultations, but said these concerns were not serious enough to make them refuse to participate. They wanted to help find out if the CCT program was effective. All HPs offered practical objections to the program, e.g., that lack of funding might make this type of CCT impossible to broadly implement.

No HP thought the CCT program would convince reluctant women to adhere to pregnancy follow-up. Instead, they emphasized factors like early follow-up, regular calls, and comprehensive individualized care.

\section{Discussion}

All women who received the CCT intervention viewed it positively and spent the money on their children and families. Most of participating women (13) affirmed that they controlled the cash payments and that the money did not go to their husbands. No woman who received the intervention said she felt stigmatized by the payments. Women who did not receive the intervention were surprised that CCT could be an option. Even healthcare providers (HP) who thought testing the CCT program was worthwhile were concerned about the ethics of payment because they felt it disrupted the principle of equality and might be stigmatizing. On a practical level, all HP said that France's underfunded health system might better spend the money on other interventions to attract and retain women in pre- and antenatal care.

The responses we received from women in the CCT program indicated that the payments had improved their lives. These results align with other studies from other countries showing CCT improved the daily lives of women and children $(15,25,26)$. Likewise, our results align with studies that show that women in precarious situations mainly use their income for daily child-related expenses $(27,28)$. All women in the control group found the idea of receiving money to attend their consultations surprising and even inappropriate, but the high level of approval voiced by women in the program suggests that initial 
negative reactions might grow more positive with exposure, especially since women in the control group welcomed cash payment for the interview and also said they would spend it on their children.

HP accept randomized trials as the standard for assessing the effectiveness of medications, but randomized trials are not yet as widely accepted for assessing economic or social interventions $(25,26$, 27), which may explain why HP were so concerned about disrupting equality by compensating participants in the intervention group but not in the control group. Though HP were worried that the CCT program would stigmatize vulnerable individuals (32), the women who received payments did not feel this way. All of them thought they benefited from the payments during pregnancy, so the beliefs of HPs about the stigma of cash payments may be incorrect and in need of adjustment.

To successfully test new economic and social methods for improving patient management during pregnancy and early motherhood, especially for women in precarious situations, we need to proactively encourage buy-in from the professionals who will deliver these interventions. It may be possible to accomplish this by shifting managerial paradigms (33) or by developing new health organizations, by redefining the roles of health professionals and patients, and by co-constructing an adapted follow-up procedure $(34,35)$. Health professionals may need to be convinced that recipients experience financial incentives as a redistribution of wealth to those who need it and not as a stigma.

Though we interviewed HPs before the Covid-19 outbreak, the pandemic has only exacerbated the funding crisis in French public hospitals. Even before the epidemic, HP argued that offering patients cash was a misallocation of resources that should be devoted to more effective measures to improve care. All HP did not believe that the CCT program was the best way to ensure women attended their consultations. They think it would be better to improve car and support by, e.g., hiring more doctors and midwives and improving patient management $(20,21)$. HP preferred spending money on dedicated units that treated women in the proper context and on staffing them well enough to follow up women who miss appointments. Their views align with findings that the most effective interventions make it easier for patients to navigate care during pregnancy (38-40). However, Salam's study (41) showed that in some situations CCT programs have a greater impact on women's behavior than other actions

Though women who received CCT unanimously maintained that the payments did not affect their attitudes towards medical follow-up during pregnancy, we cannot verify this until the NAITRE study gives us empirical evidence about the effectiveness of the CCT program. If attendance in both intervention and control are the same, we will know payments of this size do not encourage women to attend. But if women in the CCT program have higher attendance to follow-up, this would suggest that the women we interviewed felt social pressure to deny that the money had any effect on their actions. We expect to be able to report on these results in June 2021.

Our study had some limitations. Because women who did not adhere to prenatal follow-up were difficult to include in our qualitative survey (many did not return our phone calls), our sample included too few non-adherent women to adequately represent their perspective. As the qualitative study was conducted primarily in university hospitals, women with difficult pregnancies (pre-eclampsia, prematurity) may have 
been over-represented. These women may be more aware of the usefulness of antenatal care. Because of the NAITRE trial's inclusion criteria, we could not interview women who came to give birth without any follow-up during pregnancy. Our finding that financial incentives did not lead to stigmatization cannot be generalized to the most precarious women (those without any social security coverage) because the NAITRE study did not include them. All women in NAITRE had already taken the administrative steps to document their low financial status and to gain access to dedicated health insurance (CMU or AME), so we may have selected for women who were willing to publicly acknowledge their financial limitations. Because we decided to interview health professionals two years after we began to include women, many of the physicians who refused to participate in NAITRE had changed departments and were unreachable, so it is possible that we underestimated the strength of health professionals' opposition to a CCT approach.

To provide high quality pre- and antenatal care, we must follow up women who do not attend their appointments, but follow-up by phone may not be sufficient to ensure that women who need this care attend their consultations. Our experience with NAITRE suggests that many women, especially those who are non-adherent, are difficult or impossible to reach by phone. Their social and economic vulnerability may make them even less accessible. Sending HP into the field to locate these women and providing incentives like CCT may help them overcome economic barriers to attendance. We need more studies to determine the benefits of CCT for women of low socioeconomic status and to determine its costeffectiveness.

\section{Conclusion}

In France, where prenatal follow-up is free, health professionals questioned the ethics of using a CCT to improve medical follow-up during pregnancy, but women who received a cash incentive said they did not feel stigmatized and indicated that these payments helped them prepare for their baby's birth.

\section{Abbreviations}

AME

Aide Médicale d'Etat; State Medical Coverage or

ATM

Automated teller machine

CCT

Cash Transfer Program

$\mathrm{CMU}$

couverture médicale universelle / Universal Medical Coverage

HP

Health Professional

WHO

World Health Organization

Page $11 / 21$ 


\section{Declarations}

\section{Ethics approval and consent to participate}

The participants all agreed to participate in this study after reading an "information note" describing the purpose, method and use of the data (analysis and publication). Consent for publication

\section{Competing interests}

Authors has no competing interest to declare

\section{Funding}

This study was funded by the French Ministry of Health (PREPS).

\section{Availability of data and material}

Data are available upon request to the first author (amarceau@chu-besancon.fr). Data available: transcript interviews, analysis table

\section{Funding}

This study was funded by the French Ministry of Health (PREPS).

\section{Authors' Contributions}

Aurélie Godard-Marceau (Ph.D): substantial contributions to the conception; collect of data, analysis; interpretation of data; drafted the work.

Nicolas Meunier Beillard (M.A.): substantial contributions to the conception; collect of data, analysis; interpretation of data; drafted the work

Philippe Deruelle, Mathieu Morin, Claude Virtos, Astrid Eckman-Lacroix, and Thomas Schmitz: Inclusions of participants, revised the work

Laurent Laforet: contribution to collect of data, monitoring, revised the work

Marc Bardou(M.D., Ph.D): conception of the study, substantively revised the work

\section{Acknowledgment}

The authors thank Suzanne Rankin from Dijon-Bourgogne University Hospital for English language editing of the manuscript.

The authors would like to express their gratitude to the women who participated in the NAITRE study, and particularly agreed to participate in the qualitative survey, as well as to the health professionals who took 
care of the mother and their babies.

\section{Competing Interests}

The investigators have no conflicts of interest to declare.

\section{References}

1. Crone MR, Luurssen-Masurel N, Bruinsma-van Zwicht BS, van Lith JMM, Rijnders MEB. Pregnant women at increased risk of adverse perinatal outcomes: A combination of less healthy behaviors and adverse psychosocial and socio-economic circumstances. Prev Med. 2019;127:105817.

2. Glassman A, Duran D, Fleisher L, Singer D, Sturke R, Angeles G, et al. Impact of conditional cash transfers on maternal and newborn health. J Health Popul Nutr. déc 2013;31(4 Suppl 2):48-66.

3. Azria E, Blondel B, Estellat C, Luton D, Oury J-F, Schmitz T, et al. Association between prenatal care utilization and severe perinatal and maternal morbidities: an analysis within the precare cohort: 632 . Am J Obstet Gynecol [Internet]. janv 2017 [cité 18 oct 2019];216(1). Disponible sur: insights.ovid.com

4. Blondel B, Lelong N, Kermarrec M, Goffinet F, National Coordination Group of the National Perinatal Surveys. Trends in perinatal health in France from 1995 to 2010. Results from the French National Perinatal Surveys. J Gynecol Obstet Biol Reprod (Paris). juin 2012;41(4):e1-15.

5. Brugier C, Morel O, Ricbourg A, Bréchat PH, Gayat E, Barranger E. [Impact of precariousness on quality of prenatal detection: Lariboisière hospital experience in Paris]. J Gynecol Obstet Biol Reprod (Paris). sept 2012;41(5):454-9.

6. Larrañaga I, Santa-Marina L, Molinuevo A, Álvarez-Pedrerol M, Fernández-Somoano A, JimenezZabala A, et al. Poor mothers, unhealthy children: the transmission of health inequalities in the INMA study, Spain. Eur J Public Health. 1 juin 2019;29(3):568-74.

7. WHO | New guidelines on antenatal care for a positive pregnancy experience [Internet]. WHO. World Health Organization; [cité 25 mai 2020]. Disponible sur:

http://www.who.int/reproductivehealth/news/antenatal-care/en/

8. Grossesse: première consultation et suivi mensuel [Internet]. [cité 25 mai 2020]. Disponible sur: https://www.ameli.fr/assure/sante/themes/grossesse/consultation-suivi-mensuel

9. Dadi AF, Miller ER, Woodman RJ, Azale T, Mwanri L. Effect of antenatal depression on adverse birth outcomes in Gondar town, Ethiopia: A community-based cohort study. PLOS ONE. 17 juin 2020;15(6):e0234728.

10. Saleh L, Shareef M, Meiracker AH van den, Visser W. The impact of implementing the WHO-2013 criteria for gestational diabetes mellitus on its prevalence and pregnancy outcomes: A comparison of the WHO-1999 and WHO-2013 diagnostic thresholds. Eur J Obstet Gynecol Reprod Biol. juin 2020;249:107.

11. Moresi S, Martino C, Salvi S, Del Sordo G, Fruci S, Garofalo S, et al. Perinatal outcome in gestational hypertension: Which role for developing preeclampsia. A population-based cohort study. Eur J Obstet 
Gynecol Reprod Biol. août 2020;251:218-22.

12. Heil Sh, Hand D, Sigmon S, Badger G, Meyer M, Higgins H. Using behavioral economic theory to increase use of effective contraceptives among opioid-maintained women at risk of unintended pregnancy. Prev Med. 23 juin 2016;92:62-7.

13. Edmond KM, Foshanji Al, Naziri M, Higgins-Steele A, Burke JM, Strobel N, et al. Conditional cash transfers to improve use of health facilities by mothers and newborns in conflict affected countries, a prospective population based intervention study from Afghanistan. BMC Pregnancy Childbirth. 3 juin 2019;19(1):193.

14. Rawlings LB. Evaluating the Impact of Conditional Cash Transfer Programs. World Bank Res Obs. 1 mars 2005;20(1):29-55.

15. Oduenyi C, Ordu V, Okoli U. Assessing the operational effectiveness of a maternal and child health $(\mathrm{MCH})$ conditional cash transfer pilot programme in Nigeria. - Abstract - Europe PMC [Internet]. [cité 19 déc 2019]. Disponible sur: https://europepmc.org/article/med/31419952

16. Nery JS, Pereira SM, Rasella D, Penna MLF, Aquino R, Rodrigues LC, et al. Effect of the Brazilian Conditional Cash Transfer and Primary Health Care Programs on the New Case Detection Rate of Leprosy. PLoS Negl Trop Dis. 20 nov 2014;8(11):e3357.

17. Gertler P. Do Conditional Cash Transfers Improve Child Health? Evidence from PROGRESA's Control Randomized Experiment. Am Econ Rev. avr 2004;94(2):336-41.

18. Fernald LCH, Gertler PJ, Neufeld LM. The Importance of Cash in Conditional Cash Transfer Programs for Child Health, Growth and Development: Lancet. 8 mars 2008;371(9615):828-37.

19. Noordraven EL, Wierdsma Al, Blanken P, Bloemendaal AFT, Staring ABP, Mulder CL. Financial incentives for improving adherence to maintenance treatment in patients with psychotic disorders (Money for Medication): a multicentre, open-label, randomised controlled trial. Lancet Psychiatry. 2017;4(3):199-207.

20. Vaz-Carneiro A, Costa J. [Analysis of the Cochrane Review: Incentives for Smoking Cessation. Cochrane Database Syst Rev. 2015;5:CD004307]. Acta Med Port. janv 2016;29(1):12-4.

21. Triyana $\mathrm{M}$, Shankar $\mathrm{AH}$. The effects of a household conditional cash transfer programme on coverage and quality of antenatal care: a secondary analysis of Indonesia's pilot programme. BMJ Open. oct 2017;7(10):e014348-e014348.

22. Till SR, Everetts D, Haas DM. Incentives for increasing prenatal care use by women in order to improve maternal and neonatal outcomes. Cochrane Database Syst Rev. 15 déc 2015; (12):CD009916.

23. Berlin N, Goldzahl L, Jusot F, Berlin I. Protocol for study of financial incentives for smoking cessation in pregnancy (FISCP): randomised, multicentre study. BMJ Open. 1 juill 2016;6(7):e011669.

24. Bardou M, Crépon B, Bertaux A-C, Godard-Marceaux A, Eckman-Lacroix A, Thellier E, et al. NAITRE study on the impact of conditional cash transfer on poor pregnancy outcomes in underprivileged women: protocol for a nationwide pragmatic cluster-randomised superiority clinical trial in France. BMJ Open. 1 oct 2017;7(10):e017321. 
25. Tonguet-Papucci A, Houngbe F, Lompo P, Yameogo WME, Huneau J-F, Ait Aissa M, et al. Beneficiaries' perceptions and reported use of unconditional cash transfers intended to prevent acute malnutrition in children in poor rural communities in Burkina Faso: qualitative results from the MAM'Out randomized controlled trial. BMC Public Health [Internet]. 30 mai 2017 [cité 25 juill 2019];17. Disponible sur: https://www.ncbi.nlm.nih.gov/pmc/articles/PMC5450256/

26. Hjelm L, Handa S, de Hoop J, Palermo T, Zambia CGP and MCP Evaluation Teams. Poverty and perceived stress: Evidence from two unconditional cash transfer programs in Zambia. Soc Sci Med 1982. 2017;177:110-7.

27. LE TRAVAIL DES FEMMES EN GUINÉE MARITIME - De l'organisation sociale à l'organisation économique, Aurélie Godard - livre, ebook, epub [Internet]. [cité 30 juill 2019]. Disponible sur: http://www.editions-harmattan.fr/index.asp?navig=catalogue\&obj=livre\&no=31456\&razSqIClone=1

28. Travail et genre dans le monde, l'état des savoirs - Margaret MARUANI - Éditions La Découverte [Internet]. [cité 21 oct 2019]. Disponible sur: https://www.editionsladecouverte.fr/catalogue/indexTravail_et_genre_dans_le_monde_l_etat_des_savoir-9782707174567.html

29. Bédécarrats F, Guérin I, Roubaud F. All that Glitters is not Gold. The Political Economy of Randomized Evaluations in Development. Dev Change. 2019;50(3):735-62.

30. Doligez F. L'Économie comportementale en question, Jean-Michel Servet, éditions Charles Léopold Mayer, 2018, 208 pages. RECMA. 9 oct 2018;N 350(4):114-6.

31. Kvangraven IH. Impoverished economics? A critical assessment of the new gold standard. World Dev. 1 mars 2020;127:104813.

32. Kyomuhendo GB. Indignity in Cash Transfers: The Senior Citizen's Grant in Uganda. Int J Soc Qual. 1 déc 2016;6(2):71-88.

33. Durand S, Baret C, Krohmer C. La sociologie de la traduction comme grille de recherche-intervention: le cas d'un projet de prévention des risques psychosociaux dans un hôpital public. RIMHE Rev Interdiscip Manag Homme Entrep. 14 mars 2018;n³0(1):3-28.

34. Touati N, Rodríguez C, Paquette M-A, Maillet L, Denis J-L. Professional Role Identity: At the Heart of Medical Collaboration Across Organisational Boundaries. Int J Integr Care [Internet]. [cité 22 juill 2020];19(2). Disponible sur: https://www.ncbi.nlm.nih.gov/pmc/articles/PMC6450244/

35. Jukić T, Pevcin P, Benčina J, Dečman M, Vrbek S. Collaborative Innovation in Public Administration: Theoretical Background and Research Trends of Co-Production and Co-Creation. Adm Sci. déc 2019;9(4):90.

36. Gupta A, Fledderjohann J, Reddy H, Raman VR, Stuckler D, Vellakkal S. Barriers and prospects of India's conditional cash transfer program to promote institutional delivery care: a qualitative analysis of the supply-side perspectives. BMC Health Serv Res. 25 janv 2018;18(1):40.

37. Vellakkal S, Reddy H, Gupta A, Chandran A, Fledderjohann J, Stuckler D. A qualitative study of factors impacting accessing of institutional delivery care in the context of India's cash incentive program. Soc Sci Med. 1 avr 2017;178:55-65. 
38. Austad K, Juarez M, Shryer H, Moratoya C, Rohloff P. Obstetric care navigation: results of a quality improvement project to provide accompaniment to women for facility-based maternity care in rural Guatemala. BMJ Qual Saf. 2 nov 2019;

39. Balaam M-C, Thomson G. Building capacity and wellbeing in vulnerable/marginalised mothers: A qualitative study. Women Birth. 1 oct 2018;31(5):e341-7.

40. Coleman J, Black V, Thorson AE, Eriksen J. Evaluating the effect of maternal mHealth text messages on uptake of maternal and child health care services in South Africa: a multicentre cohort intervention study. Reprod Health. 20 oct 2020;17(1):160.

41. Salam RA, Lassi ZS, Das JK, Bhutta ZA. Evidence from district level inputs to improve quality of care for maternal and newborn health: interventions and findings. Reprod Health. 4 sept 2014;11(2):S3.

\section{Tables}

Table 1 : Distribution of respondent groups

\begin{tabular}{|llll|}
\hline & Intervention & Control & Total \\
\hline Besançon & 3 & 3 & 6 \\
\hline Paris & 4 & 6 & 10 \\
\hline Lille & 5 & 1 & 6 \\
\hline Toulouse & 2 & - & 2 \\
\hline Dreux & - & 2 & 2 \\
\hline Total & 14 & 12 & 26 \\
\hline
\end{tabular}

Table 2: Characteristics of the women 


\begin{tabular}{|ll|}
\hline & $\mathrm{N}=26$ \\
\hline average age & 31 \\
\hline median age & 30 \\
\hline primiparous & 6 \\
\hline multiparous with at least 1 child at home & 20 \\
\hline Marital status & \\
\hline lives alone & 2 \\
\hline lives with a spouse & 24 \\
\hline Precarious housing & \\
\hline yes & 4 \\
\hline no & 22 \\
\hline Professional situation & \\
\hline Craftsmen, sales persons, business owners & 2 \\
\hline Students (including internship) & 2 \\
\hline Employees & 2 \\
\hline Unemployed (unemployment, housewife,...) & 20 \\
\hline
\end{tabular}

\section{Table 3 :}

Relevant Verbatim 
Women's perception of the CCT initiative

\section{Surprise}

Patient: At first, I thought it was weird, because I thought to myself why are they giving me money because I'm pregnant, I don't know..., I found it a little... I'd never seen it so I didn't know how to take it actually. On the one hand, I'm happy because it's not... how do you say, it's nice to have $30 €$ to buy something, but on the other hand I didn't understand, I thought why? But hey. (FB1)

\section{Good thing - money for her and child}

Interviewer: What did you think of this proposal when the doctor told you about it?

Patient: Well, I thought it was good. Because I've never had a credit card before, that was good. I buy, I feel like I have a card to buy what I want from time to time, it wasn't huge but it was good. (FB2)

Patient: And I thought it was interesting and one day I came home and said to my husband, "Yes, frankly that's a good system they set up because I realize that there are people, it's true that financially they can't and it's really a plus", because when you're pregnant you really want to eat special things and I realize that it helps to feel good during pregnancy and I honestly thought it was great. FP(13)

When I knew she was a girl, when I was sure [laughing], then I started buying things for her. Like the things you need in the hospital, for example, the first pack of diapers, wipes, cotton, things like that. (FB1)

I told one of my friends about it "and you know that now they do programs and such for people who have the RSA or CMU, they give $30 €$, honestly it's so good and everything "because I know I have friends they didn't eat during their pregnancy, it was tough sometimes. (FP13)
Health professionals' perception of the CCT initiative

\section{Financial aspect}

Caregiver: I told myself that... not to mix up the medical follow-up, we'll say and then the financial aspect of things. I don't know, there was something in that that that shocked me. For me, you have to separate the two, and the fact that in the end the medical staff validates the fact that that there is behind a financial side, frankly for me they mixed the genres and that's it. (PN1)

\section{Non equality between patients}

What also happened is that we have patients who know each other, who come from the same neighbourhood or the same area, and I have already had patients who said "but I don't understand, a friend of mine received money, I have nothing, what's going on?" So twice, it's not that big a deal, but there were two, so when this patient told me about it, I kind of avoided the question and said "but the study is ending", well, I don't know what I said anymore to try to...(PB2)

\section{Research}

At the time, we were just starting to set up studies in the department, because we didn't have a lot of clinical research until then, we had one or two studies in progress. And then, well, as we had practitioners that were really dedicated to obstetrics we were able to set up a little more, so we were motivated to do, to help with clinical studies. It's not that anymore. (BM)

Other way to improve follow-up

We have set up specific consultations, over a period longer than one hour, where we try to build trust and work in a multidisciplinary way, i.e. in conjunction with social workers, the PMI [Protection Maternelle et Infantile - Women and Child Care], charities if necessary, and so on. And generally, setting up these consultations finally helps to build patients' trust and to see them more regularly and in a way..., well, they come. They come for the consultation. (BSF) 


\section{Group control}

Patient: Uh, no, that's a bad idea.

Interviewer: Yes?

Patient: I don't think that's such a good idea, actually.

Interviewer: What bothers you about it?

Patient: To pay a person to go for the consultation.

Interviewer: Yes?

Patient: But wait, it's her baby, it's her baby plus it's herself, it's her health and the health of the baby you're carrying. (FP4)

\section{Importance of follow-up}

Patients: With the examinations, the follow-up, they detected, they gave me the necessary checkup and I had no problems apart from the diagnosis of pregnancy at 28 weeks it was very good again, because back home, in A[Country], I didn't do a screening for gestational diabetes and I even think, maybe I had gestational diabetes there that I didn't know, because the girl was born at $3.8 \mathrm{~kg}$. Maybe I developed gestational diabetes that I didn't even know I had. (FP22)

\section{Figures}




\section{5 head of unit contacted}

18 never answer to our mail or call

\section{7 head of unit agreed to participate}

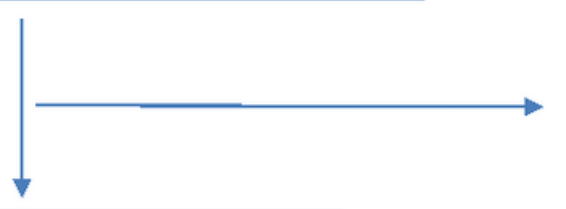

$1 \mathrm{HP}$ did not come to the meeting and then said he did not have time for interview

7 interviews with HP in 6 unit

\section{Figure 1}

3 centers (Besançon, Lille, Robert Debré)

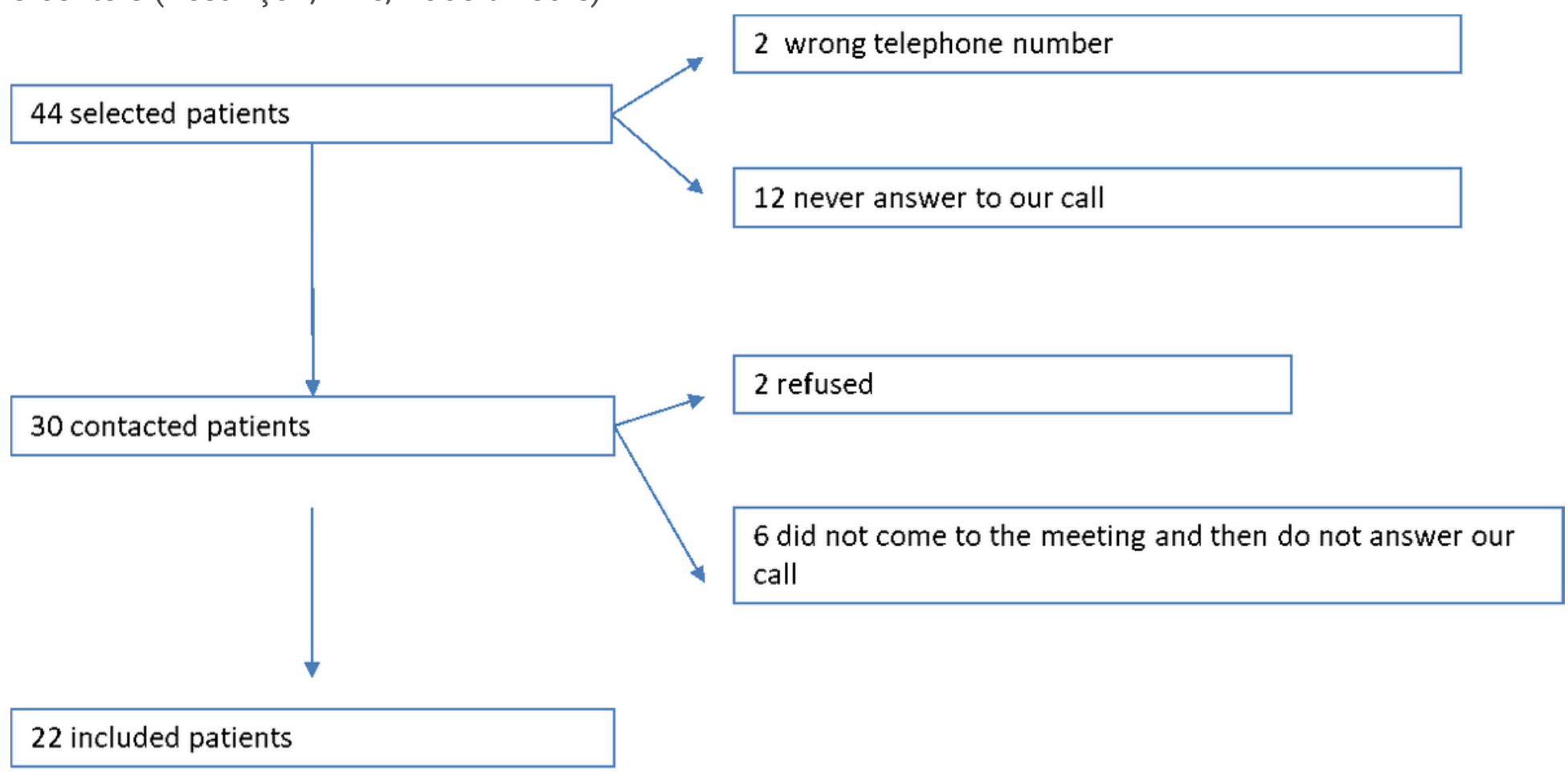

Figure 2

Others centers 
4 included patients

Figure 3

Health Professionals

\section{Supplementary Files}

This is a list of supplementary files associated with this preprint. Click to download.

- NAITRECOREQChecklist.doc 